DOI: 10.4274/jarem.galenos.2021.09719

J Acad Res Med 2021;11(2):169-73

\title{
Comparison of ESWL and RIRS for 2 Cm Lower Pole Renal Pelvis and Kidney Stones in Preschool Children
}

\author{
(D) Mehmet Eflatun Deniz¹, (D) Ali Çift2 \\ ${ }^{1}$ Adıyaman Kahta State Hospital, Clinic of Urology, Adıyaman, Turkey \\ ${ }^{2}$ Adıyaman Training and Research Hospital, Clinic of Urology, Adıyaman, Turkey
}

\begin{abstract}
Cite this article as: Deniz ME, Çift A. Comparison of ESWL and RIRS for $2 \mathrm{Cm}$ Lower Pole Renal Pelvis and Kidney Stones in Preschool Children. J Acad Res Med 2021;11(2):169-73
\end{abstract}

\begin{abstract}
Objective: Surgically treating urinary tract stones in paediatric patient groups, especially in the preschool period, is more difficult than that in adult patient groups. For paediatric patients, non-invasive methods have many advantages and disadvantages. In this study, we compared the success rates of extracorporeal shock wave lithotripsy (ESWL) and retrograde intrarenal surgery (RIRS) for the treatment of lower pole renal pelvis and kidney stones.

Methods: Patients who had lower pole renal pelvis and kidney stones and were subjected to RIRS and ESWL in our clinic between March 2016 and October 2019 were retrospectively reviewed. The success rates and duration of anaesthesia were compared in terms of the size, localisation and hardness of the stones.

Results: Surgical success was achieved in 17 (80.9\%) of 21 patients who underwent RIRS in the study and in 14 (73.6\%) of 19 patients who had ESWL. No relationship was found amongst the size, location, Hounsfield degree and stone-free (SF) rate in either of the methods. RIRS and ESWL had $50 \%$ and $60 \%$ SF in the lower pole of the kidney, respectively. Conversely, the SF rate in the renal pelvis was around $80 \%$. The anaesthesia duration for RIRS was longer in the successful cases than in the unsuccessful ones, whereas it was just the opposite in ESWL group so anaesthesia duration was longer in the unsuccessful cases.

Conclusion: ESWL and RIRS can be successfully applied to preschool children. They have similar success rates in terms of stone treatment. Therefore, the optimal technique should be used individually in each patient.
\end{abstract}

Keywords: Preschool age, paediatrics, urinary stones, RIRS, ESWL, stone location

\section{INTRODUCTION}

Managing urinary tract stones is crucial in paediatric patients. In this group, recurrences are common, but an underlying metabolic factor may be present. Although children cannot localise pain, they can visit a hospital and complain of abdominal pain. Typically, they may present with haematuria and symptoms such as dysuria and fever. In some cases, only urinary tract infection can be detected (1). Although this condition can be most accurately diagnosed with non- contrast abdominal tomography, urinary ultrasound should be performed primarily because of radiation exposure $(2,3)$. Treatment methods are planned according to the location and size of stones. However, treatment for children is more difficult than that for adults because thin-walled instruments are needed for their anatomical structures, and anaesthesia is required for extracorporeal shock wave lithotripsy (ESWL). Furthermore, children may be exposed to radiation. As such, preschool children are the most difficult patient group. In this

ORCID IDs of the authors: M.E.D. 0000-0003-2570-3784; A.Ç. 0000-0002-2329-0149. 
study, we aimed to compare ESWL and retrograde intrarenal surgery (RIRS) in paediatric patients with lower pole renal pelvis and kidney stones of less than $2 \mathrm{~cm}$.

\section{METHODS}

Patients who underwent ESWL and RIRS in our clinic between March 2016 and October 2019 were retrospectively reviewed. We picked radiopaque, under $20 \mathrm{~mm}$ renal pelvis and lower pole stones, aged $\leq 6$ years patients and excluded the ones who has a ureteral stent history in their past. Patients aged $>6$ years and having stones in different localisations were excluded. ESWL was performed by a urologist and a technician. Patients' stone size, location, degree of hardness [Hounsfield unit (HU)], duration of fluoroscopy and anaesthesia, stone-free (SF) and success rates were recorded and statistically compared. Their urine cultures were sterilised before the procedures. The patients were evaluated by anaesthesiologists to check any disease or drug use. None of them had a history of undergoing previous surgical procedures.

All surgeries were performed using $7.95 \mathrm{Fr}$ urf-p6 digital ureteroscopes, 8.5 Fr digital ureteroscopes and Flex- $X^{c}$ flexible ureteroscopes. A 9.5-11.5 Fr $20 \mathrm{~cm}$ ureteral access sheet was used as an accessory sheet for children. A holmium YAG laser with 30 Watts, 16 mAmps and 50/60 Hz was used. Cystoscopy was conducted in a lithotomy position, and a hydrophilic tipped guide wire was moved forward into the ureter. Control ureteroscopy with the help of semirigid ureterorenoscopy (7.5 Fr) was carried out over this guidewire to exclude ureteral pathologies and stone and perform dilatation. Afterwards, the access sheath was advanced over the guidewire until the proximal ureter was reached. The renal pelvis was reached with a flexible ureterorenoscope over the guidewire, and the stones were fragmented with the holmium YAG laser. When the kidney could not be accessed because of stenosis, a double J stent (DJ) was placed in the ureter, and the procedure was repeated 4 weeks later. The stones were fragmented until they reached a size that could fall spontaneously. At the end of the procedure, a $3 \mathrm{Fr}$ double $\mathrm{J}$ ureteral stent was placed in the patients if necessary.

All the patients in the ESWL group were intubated under anaesthesia. ESWL was performed using a ModularisVario, which is a mobile, fully integrated, next-generation lithotripter with an electromagnetic shock wave source and a fully integrated fluoroscopic guided device. Energy levels were initially set at E0.1 and gradually increased to a maximum of E8.0 in 38 steps. Average energy level, maximum energy level and total energy delivered were displayed automatically at the end of each session. The patients were treated in a supine position. Fluoroscopy was performed to localise the stones. A lubricating gel was applied on the area to be subjected to ESWL. In each ESWL session, shocks between 1,500 and 2,000 at a frequency of $60 \mathrm{~Hz}$ were given. Shock wave number, shock wave intensity and shock wave energy were recorded.

Before the procedure, detailed information was given to all the patients, and their consents were obtained. All the cases were outpatients. Oral paracetamol was prescribed to alleviate pain. On the $10^{\text {th }}$ day after ESWL, the patients were called for control visit. Residual stones were checked via plain abdominal radiography. Another session was planned for those with residues. The total duration of anaesthesia and fluoroscopy of the patients who had a maximum of three ESWL sessions was recorded. Patients without residual stones ( $0 \mathrm{~mm}$, i.e. SF) were considered to be successfully treated. This study was approved by the Adıyaman University Non-Invasive Clinical Research Ethics Committee (decision no: 2020/11-21, date: 22.12.2020).

\section{Statistical Analysis}

Categorical measurements were summarised as numbers and percentages, and numerical measurements were presented as mean and standard deviation. Chi-square test (Pearson chi-square or Fisher's Exact test) was conducted to compare categorical measurements between groups. Shapiro-Wilk test was performed to determine whether numerical measurements provided the assumption of normal distribution. In the comparison of numerical measurements between the groups, a t-test was used in independent groups if the assumptions were met. Otherwise, Mann-Whitney U test was applied. Kruskal-Wallis test was utilised for the general comparison of numerical measurements of more than two groups. Mann-Whitney $U$ test with Bonferroni correction was conducted for pairwise group comparisons. Data were statistically analysed with SPSS version 20.0 (IBM) and considered significant at a 0.05 level in all the tests.

\section{RESULTS}

The average age of the patients who underwent RIRS was $4.5 \pm 1.1$ years. Amongst these patients, 13 were boys, and 8 were girls. Furthermore, 12 had stones in the right kidney, and 9 had stones in the left kidney. In addition, 4 had stones in the lower pole, and 17 had stones in the renal pelvis. The mean stone diameter was $13.6 \pm 1.5 \mathrm{~mm}$.

The average age of the patients who underwent ESWL was $4.7 \pm 1.4$ years. Amongst them, 12 were boys, and 7 were girls. Furthermore, 9 had stones in the right kidney, and 10 had stones in the left kidney. Moreover, 5 had stones in the lower pole of the kidney, and 14 had stones in the renal pelvis. The mean stone diameter was $10.1 \pm 3.2 \mathrm{~mm}$.

Surgical success was achieved in 17 (80.9\%) of 21 patients who were subjected to RIRS. In 13 of the patients (61.9\%) who had RIRS, a DJ stent was placed initially (preop DJ +), and RIRS was then performed due to ureteral stricture. No statistical difference was found after the success was evaluated in patients who had preop DJ (-; Table 1).

The size and location of the stones were not related to the degree of $\mathrm{HU}$ and SF in either method (Table 2). No significant relationship was found between the number of times of ESWL and HU (Table 3). In RIRS and ESWL, 50\% and 60\% SF were detected in the lower pole of the kidney, respectively. By comparison, the SF rate in the renal pelvis was around $80 \%$. Even when the stone size 
was divided into two groups ( $10 \mathrm{~mm}$ below and $10 \mathrm{~mm}$ above), the success rates of the methods had no difference (Table 4).

The duration of anaesthesia was examined in terms of success rate. The results revealed that the average duration of anaesthesia in the ESWL was almost one-third of successful RIRS. Conversely in unsuccessful cases, anaesthesia duration was longer in ESWL when it was compared to RIRS. The average duration of anaesthesia in ESWL is almost three times more than that in RIRS (Table 5; Figure 1).

\section{DISCUSSION}

Endourology plays an increasingly vital role in urological surgery. As the number of non-invasive procedures performed on patients increase, their hospitalisation time, post-operative pain and recovery time gradually decrease. Surgical experience increases success rates and lead to good results. In addition to the successful rates of ESWL in preschool children, the results of RIRS are excellent in terms of patient satisfaction. Our data on the surgical procedures performed revealed that the success rate of RIRS was $80.9 \%$, which was similar to that reported in

\section{Table 1. DJ-SF rate relationship}

\begin{tabular}{|l|l|l|l|}
\hline & $\begin{array}{l}\text { SF+ } \\
\mathbf{n = 4}\end{array}$ & $\begin{array}{l}\text { SF- } \\
\mathbf{n = 1 7}\end{array}$ & $\mathbf{p}$ \\
\hline Preop DJ- & $0(0 \%)$ & $8(100 \%)$ & 0.131 \\
\hline Preop DJ+ & $4(31 \%)$ & $9(69 \%)$ & \\
\hline \multicolumn{2}{l|}{ SF: stone-free, DJ: double J stent } \\
\hline
\end{tabular}

\section{Table 2. Patients who underwent RIRS and ESWL}

\begin{tabular}{|c|c|c|c|}
\hline & $\begin{array}{l}\text { No success } \\
n=4\end{array}$ & $\begin{array}{l}\text { Success } \\
n=17\end{array}$ & $p$ \\
\hline Stone size & $13.3 \pm 2.8$ & $13.8 \pm 1.3$ & 0.737 \\
\hline \multicolumn{4}{|c|}{ Stone location } \\
\hline Lower pole & $2(50 \%)$ & $2(50 \%)$ & \multirow{2}{*}{0.148} \\
\hline Pelvis & 2 (12\%) & 15 (88\%) & \\
\hline \multirow[t]{2}{*}{$\mathrm{HU}$} & $725.0 \pm 188.2$ & $865.1 \pm 191.2$ & 0.202 \\
\hline & $n=5$ & $n=14$ & \\
\hline Stone size & $11.6 \pm 5.4$ & $9.7 \pm 2.1$ & 0.476 \\
\hline \multicolumn{4}{|c|}{ Stone location } \\
\hline Lower pole & $2(40 \%)$ & $3(60 \%)$ & \multirow{2}{*}{0.570} \\
\hline Pelvis & $3(21 \%)$ & 11 (79\%) & \\
\hline $\mathrm{HU}$ & $674.8 \pm 389.5$ & $627.0 \pm 222.9$ & 0.754 \\
\hline
\end{tabular}

\section{Table 3. ESWL-HU relationship}

\begin{tabular}{|l|l|l|l|l|}
\hline \multicolumn{4}{|c|}{ Number of ESWL sessions } \\
\hline & $\mathbf{1}$ & $\mathbf{2}$ & $\mathbf{3}$ & \\
$\mathrm{n}=9$ & $\mathrm{n}=4$ & $\mathrm{n}=6$ & $\mathrm{p}$ \\
\hline $\mathrm{HU}$ & $616.8 \pm 215.2$ & $645.5 \pm 301.5$ & $669.8 \pm 348.6$ & 0.900 \\
\hline HU: Hountsfied unit \%, ESWL: extracorporeal shock wave lithotripsy
\end{tabular}

other studies. For instance, Mokhless et al. (4) performed a randomised prospective study and obtained $86.6 \%$ success rate. Wang et al. (5) and Berrettini et al. (6) achieved $86.7 \%$ and $81.2 \%$ success rates, respectively. Baş et al. (7) found $86.2 \% \mathrm{SF}$ rate. However, studies have yet to present a consensus on the acceptable length (in millimetres) of residues to indicate the success of a procedure. In some studies, residual stones with a length of up to $3 \mathrm{~mm}$ can be acceptable and indicative of surgical success. Although the diameter of a ureter is smaller in children, stones can be dropped more easily in clinical practice than those in adults. Mokhless et al. (4) could not find a statistically significant difference in the success rate between RIRS and ESWL. In our study, the success rates of the two groups did not also differ in terms of location, size and HU.

The diameter of the ureteral lumen is an important factor in RIRS. An insufficient width causes an increase in intrarenal pressure during the procedure and consequently exacerbates complications. As such, the ureter should have an appropriate width, and a sheath must be placed before stones are fragmented. A short ureteral diameter, especially in the age group of $0-6$ years, is one of the reasons that can determine the difficulty level of surgery. In our study, the success rate was $100 \%$ in patients with preop DJ (-), but the number of patients was insufficient to show the lower success

\section{Table 4. ESWL versus RIRS}

\begin{tabular}{l|l|l|l|l|}
\hline Stone location & & No success & Success & p \\
\hline Lower pole & ESWL & $2(40 \%)$ & $3(60 \%)$ & 0.999 \\
\hline Relvis & ESWL & $2(50 \%)$ & $2(50 \%)$ & \\
\hline Stone size & RIRS & $2(12 \%)$ & $11(79 \%)$ & 0.636 \\
\hline$\leq 10 \mathrm{~mm}$ & ESWL & $3(25 \%)$ & $9(75 \%)$ & 0.308 \\
\hline$>10 \mathrm{~mm}$ & RIRS & $1(100 \%)$ & $0(0 \%)$ & \\
\hline $\begin{array}{l}\text { RIRS: retrograde } \\
\text { lithotripsy }\end{array}$ & ESWL & $2(29 \%)$ & $5(71 \%)$ & 0.580 \\
\hline & RIRS & $3(15 \%)$ & $17(85 \%)$ & \\
\hline
\end{tabular}

\section{Table 5. Durations of both methods}

\begin{tabular}{|c|c|c|c|}
\hline & $\begin{array}{l}E S W L \\
n=19\end{array}$ & $\begin{array}{l}\text { RIRS } \\
n=21\end{array}$ & $p$ \\
\hline $\begin{array}{l}\text { Duration of anaesthesia } \\
\text { (minute \%) }\end{array}$ & $92.3 \pm 96.3$ & $95.7 \pm 35.5$ & 0.054 \\
\hline Successful sessions & $\begin{array}{l}E S W L \\
n=14\end{array}$ & $\begin{array}{l}\text { RIRS } \\
n=17\end{array}$ & \\
\hline $\begin{array}{l}\text { Duration of anaesthesia } \\
\text { (minute \%) }\end{array}$ & $38.4 \pm 19.2$ & $95.3 \pm 39.3$ & $<0.001$ \\
\hline Unsuccessful sessions & $\begin{array}{l}E S W L \\
n=5\end{array}$ & $\begin{array}{l}\text { RIRS } \\
n=4\end{array}$ & \\
\hline $\begin{array}{l}\text { Duration of anaesthesia } \\
\text { (minute \%) }\end{array}$ & $243.0 \pm 44.1$ & $97.5 \pm 12.6$ & 0.016 \\
\hline
\end{tabular}




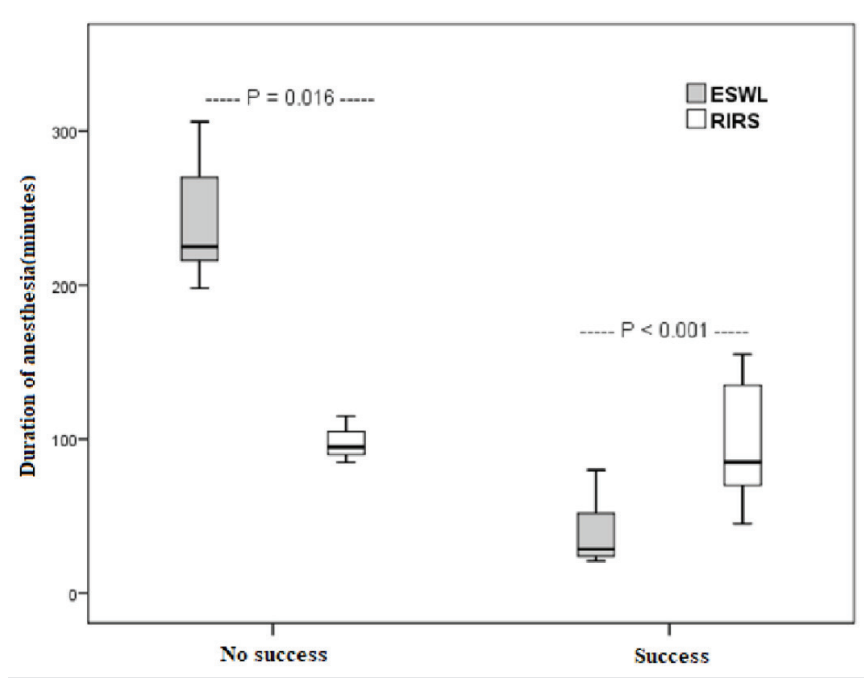

Figure 1. Relationship of RIRS and ESWL with anaesthesia RIRS: retrograde intrarenal surgery, ESWL: extracorporeal shock wave lithotripsy

rate of patients with preop DJ (+). However, these findings could not support the assumption that preop DJ $(+)$ decreased the success. Twenty-one patients were required per group to obtain a strong test result, but this result would be significant if the number of patients was three to four times higher. In some studies, a DJ catheter is placed in each patient for a while before RIRS. Therefore, this procedure should be performed depending on patients' preference. If necessary, a DJ should be used, and the procedure should be delayed until the next session.

A successful RIRS was completed in 95.3 min, but unsuccessful ones lasted $97.5 \mathrm{~min}$. The total time of ESWL was $92.3 \mathrm{~min}$. Berrettini et al. (6) found that successful and unsuccessful RIRS are completed in 95.8 and 108.3 min, respectively. Freton et al. (8) compared RIRS and ESWL and observed that the RIRS operation time is statistically longer, i.e. 28.9 min versus $105 \mathrm{~min}$. This difference is attributed to lower pole stones. Mokhless et al. (4) revealed that the duration of anaesthesia is significantly longer in RIRS (40 and $27.9 \mathrm{~min}$.). Wang et al. (5) observed that the duration of RIRS is $48 \mathrm{~min}$. In our study, the duration of ESWL was long because more stone-breaking sessions were performed in many patients (52.6\%). The specified time referred to the total session duration. When the successful and unsuccessful results were examined separately, the situation changed slightly. Our analysis of the successful results showed that the duration of ESWL was significantly shorter than that of RIRS. Conversely, in the unsuccessful group, the duration of the former was significantly longer than that of the latter. Therefore, when the stones were not fragmented in the first session, the possibility of being fragmented in the following sessions was low. After one session of ESWL, patients should be re-evaluated, and surgeons should consider if they need to continue the sessions or to change the procedure to RIRS. Interestingly, no relationship was found between the hardness of stones and the success of ESWL. If the number of patients was higher than that included in our study, then a different result would have been obtained.

Berrettini et al. (6) found SF in 2 of 3 stones in the renal pelvis and 7 of 9 stones in the lower kidney during RIRS. They could not find a significant difference between the location of stones and the success of the operation. However, when the stones were divided into two groups ( $16 \mathrm{~mm}$ and $<16 \mathrm{~mm}$ ), the success of the operation decreased significantly as the size of the stone increased. Our analysis showed no difference in the success between ESWL and RIRS in neither the lower pole of the kidney nor the renal pelvis even when the stone sizes were divided into two groups $(\geq 10$ $\mathrm{mm}$ and $<10 \mathrm{~mm}$ ). The success between these two methods was not significantly different. Therefore, both methods were equally efficient. In patients undergoing ESWL, lower pole renal pelvis stones could not easily fall spontaneously after the procedure, thereby reducing the SF rate. The disadvantage of RIRS is that the flexion capacity of the URS is limited, especially in the presence of a laser fibre. These disadvantages of lower pole stones in the two procedures might be the main factor contributing to the same success rate. Although the chances of successfully removing renal pelvis stones were the same for ESWL and RIRS, ESWL could be recommended to patients as the first treatment option because it is a non-invasive procedure.

\section{Study Limitations}

This study has some potential limitations. Firstly the charts of the patients were gathered retrospectively. Secondly in order to make more accurate datas, it is necessary to study on a population with a larger number of patients.

\section{CONCLUSION}

ESWL and RIRS could be successfully used to treat preschool children. They have similar success rates in terms of the treatment of lower pole renal pelvis stones. As such, the best option should be selected on the basis of patients' preference.

Ethics Committee Approval: This study was approved by the Adıyaman University Non-Invasive Clinical Research Ethics Committee (decision no: 2020/11-21, date: 22.12.2020).

Informed Consent: Before the procedure, detailed information was given to all the patients, and their consents were obtained.

Peer-review: Externally and internally peer-reviewed.

Author Contributions: Surgical and Medical Practices - M.E.D., A.Ç.; Concept - M.E.D., A.Ç.; Design - M.E.D., A.Ç.; Data Collection and/ or Processing - M.E.D.; Analysis and/or Interpretation - A.Ç.; Literature Search - M.E.D., A.Ç.; Writing - M.E.D.

Conflict of Interest: The authors have no conflict of interest to declare.

Financial Disclosure: The authors declared that this study has received no financial support.

\section{REFERENCES}

1. Sternberg K, Greenfield SP, Williot P, Wan J. Pediatric stone disease: an evolving experience. J Urol 2005; 174: 1711-4; discussion 1714.

2. Memarsadeghi M, Heinz-Peer G, Helbich TH, Schaefer-Prokop C, Kramer $G$, Scharitzer $M$, et al. Unenhanced multi-detector row $C T$ in patients 
suspected of having urinary stone disease: effect of section width on diagnosis. Radiology 2005; 235: 530-6.

3. Kwon JK, Chang IH, Moon YT, Lee JB, Park HJ, Park SB. Usefulness of lowdose nonenhanced computed tomography with iterative reconstruction for evaluation of urolithiasis: diagnostic performance and agreement between the urologist and the radiologist. Urology 2015; 85: 531-8.

4. Mokhless IA, Abdeldaeim HM, Saad A, Zahran AR. Retrograde intrarena surgery monotherapy versus shock wave lithotripsy for stones 10 to 20 $\mathrm{mm}$ in preschool children: a prospective, randomized study. J Urol 2014; 191(Suppl 5): 1496-9.

5. Wang W, Ge Y, Wang Z, Wang L, Li J, Tian Y. Comparing micropercutaneous nephrolithotomy and retrograde intrarenal surgery in treating 1-2 cm solitary renal stones in pediatric patients younger than 3 years. J Pediatr Urol 2019; 15: 517.e1-6.
6. Berrettini A, Boeri L, Montanari E, Mogiatti M, Acquati P, De Lorenzis E, et al. Retrograde intrarenal surgery using ureteral access sheaths is a safe and effective treatment for renal stones in children weighing $<20 \mathrm{~kg}$. J Pediatr Urol 2018; 14: 59.e1-6.

7. Baş O, Dede O, Aydogmus Y, Utangaç M, Yikilmaz TN, Damar E. et al. Comparison of Retrograde Intrarenal Surgery and Micro-Percutaneous Nephrolithotomy in Moderately Sized Pediatric Kidney Stones. J Endourol 2016; 30: 765-70.

8. Freton L, Peyronnet B, Arnaud A, Tondut L, Hascoet J, Pradère B, et al. Extracorporeal Shockwave Lithotripsy Versus Flexible Ureteroscopy for the Management of Upper Tract Urinary Stones in Children. J Endourol 2017; 31: 1-6. 